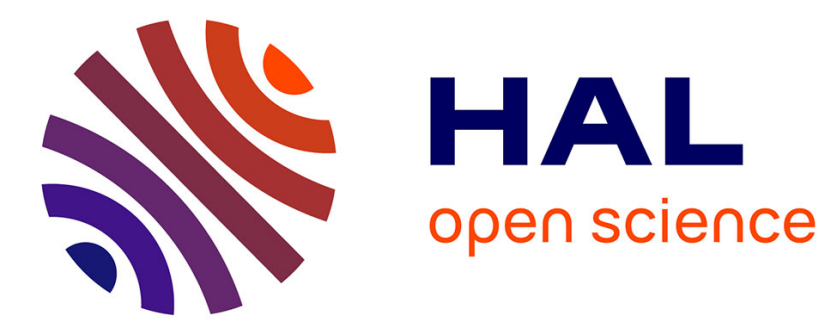

\title{
The different breeding strategies of penguins: a review
}

\author{
André Ancel, Michaël Beaulieu, Caroline Gilbert
}

\section{To cite this version:}

André Ancel, Michaël Beaulieu, Caroline Gilbert. The different breeding strategies of penguins: a review. Comptes Rendus Biologies, 2013, 336, pp.1-12. hal-00789518

\section{HAL Id: hal-00789518 https://hal.science/hal-00789518}

Submitted on 18 Feb 2013

HAL is a multi-disciplinary open access archive for the deposit and dissemination of scientific research documents, whether they are published or not. The documents may come from teaching and research institutions in France or abroad, or from public or private research centers.
L'archive ouverte pluridisciplinaire HAL, est destinée au dépôt et à la diffusion de documents scientifiques de niveau recherche, publiés ou non, émanant des établissements d'enseignement et de recherche français ou étrangers, des laboratoires publics ou privés. 


\section{Revue des différentes stratégies de reproduction des manchots} The different breeding strategies of penguins: a review

(1)

André Ancel ${ }^{a, b,{ }^{*}}$, Michaël Beaulieu ${ }^{c}$ and Caroline Gilbert ${ }^{d}$ (1)

a Université de Strasbourg, IPHC, 23 rue Becquerel, F-67087 Strasbourg, France

${ }^{\mathrm{b}}$ CNRS, UMR 7178, F-67037 Strasbourg, France

c University Freiburg, Biology I, Hauptstrasse 1, D-79104 Freiburg, Germany

d Université Paris-Est, Ecole Nationale Vétérinaire d'Alfort, UMR 7179 CNRS MNHN, 7 avenue du Général de Gaulle, F-94704 Maisons-Alfort, France

* Author and address for correspondence: André Ancel, IPHC-DEPE, UMR7178 CNRS-UdS, 23 rue Becquerel, 67087 Strasbourg, France (andre.ancel@iphc.cnrs.fr)

\section{Résumé}

Les 18 espèces de manchots vivent exclusivement dans l'hémisphère Sud, de l'Equateur jusqu'en Antarctique et subissent en conséquence différentes contraintes écologiques au cours de leur cycle reproducteur. Ceci se traduit par une forte variabilité dans tous les aspects de la biologie de la reproduction chez les différentes espèces. Bien que les manchots soient de prime abord adaptés à une vie marine, ils dépendent néanmoins d'une surface ferme pour se reproduire, élever leur progéniture et muer. Nous décrivons et comparons les cycles reproducteurs de toutes les espèces de manchots tout en mettant en avant les caractéristiques de chaque espèce que ce soit la durée de leur cycle reproducteur, le statut de la population et les menaces environnementales qui pèsent sur elle, la durée des 
différentes phases du cycle reproducteur, la fidélité du couple, la masse corporelle, la taille, la durée et les dimensions des œufs. Nous nous sommes plus particulièrement étendus sur le cycle reproducteur du genre Aptenodytes qui diffère notablement de celui des autres espèces.

\section{Abstract}

The 18 penguin species are exclusively and widely distributed in the Southern hemisphere, from the Equator to the Antarctic continent, and are thus submitted to various ecological constraints in their reproductive strategy. This results in a high variability in all aspects of the breeding biology of the different species. Although penguins appear primarily adapted for a marine existence, they remain dependent on land for breeding, rearing young and moulting. Here we describe and compare the breeding cycle of all the penguin species highlighting the characteristics of each species in terms of breeding range, population status, threats induce by environmental changes, duration of the different phases of the breeding cycle, mate fidelity, body mass, body height, egg mass and duration of egg formation. We also focus on the breeding cycle of the genus Aptenodytes since it largely differs from the breeding cycle of most of the other penguin species.

Keywords: Southern hemisphere, breeding range, mate fidelity, egg formation, reproduction, vulnerability

Mots clés: hémisphère Sud, aire de reproduction, fidélité, formation de l'œuf, reproduction, vulnérabilité

Running title: penguin's breeding cycle - le cycle reproducteur des manchots 


\section{Introduction}

Natural selection favours a breeding strategy which, in a given environment, is the most likely to ensure the production of the largest number of young which survive to breed, and the survival of parents until they breed again. The decision to breed is triggered by physiological changes set in motion by changes in the environment [1]. In birds, the timing of reproduction is determined by proximate factors and is often initiated before birds return to their breeding grounds [1,2]. Among these proximate factors, the photoperiod, the temperature, and the availability and the quality of the food required for successful breeding are frequently reported [3-6].

The majority of birds lives in a non-uniform environment (spatially and temporarily) and must breed when the conditions are the most favourable. For instance, in temperate and Polar regions, most birds have to synchronize their breeding schedule with the time of the year that will give their offspring the best chances of survival [7]. This restricted period of time dictated by resource availability leads individuals from the same population to breed synchronously. This breeding synchrony can also be associated with different advantages such as the reduction of the impact of predators and the maximisation of chick survival, by timing fledging when prey abundance is highest $[8,9]$, and/or when climatic conditions are most favourable [10].

Among seabirds, penguins are a distinctive group of flightless, long-lived pelagic seabirds. All the 18 species of penguins are grouped within a single family, the Spheniscidae. Within this family, there are six genera and each genus comprises one to eight species (Table 1). Several subspecies of little Eudyptula minor (6) and gentoo penguins Pygoscelis papua (2) have been identified $[11,12]$ but for the 
purpose of this review these penguins are considered as a single species. Some penguin species have been studied in detail, especially the Adélie penguin Pygoscelis adeliae (more than 400 papers, see ISI Web of Knowledge), but others, such as the Snares penguin Eudyptes robustus and erect-crested penguin Eudyptes sclateri have not (less than 10 publications, see ISI Web of Knowledge). Consequently, there is less information available for some species. All penguins have a similar body shape and structure. The sexes are outwardly similar in all species, though males are usually heavier, at least at the onset of the breeding season, and larger than females (Table 1). They vary considerably in height, from about 40 to $130 \mathrm{~cm}$, and in body mass, from 1 to $37 \mathrm{~kg}$ (little and emperor Aptenodytes forsteri penguins, respectively, Table 1). Such a range in body mass is only surpassed by another flightless family: the Struthioniformes, where the smallest species, the Little spotted kiwi Apteryx owenii, measures $40 \mathrm{~cm}$ and weighs $1.2 \mathrm{~kg}$ compared to the largest living ratite, the African ostrich Struthio camelus, that stands roughly $3 \mathrm{~m}$ tall and weighs $160 \mathrm{~kg}$.

Penguins are highly adapted for marine life and some species spend as little as $20 \%$ of the year on land (Fig. 1A). Nevertheless, this relatively short period on land represents one of the most important parts of their life cycle; during which penguins have to obtain a nest-site and mate, lay egg(s), rear chick(s), and moult. The 18 penguins' species share some breeding characteristics such as breeding synchrony (except for the Galápagos penguins Spheniscus mendiculus, [72]) for annual reproduction on land, and alternation of sojourns on land and at sea between partners during the chick-rearing period. An important characteristic of all penguin species is their ability to withstand prolonged period of fasting, on land or sea-ice, during breeding. With the exception of the yellow-eyed penguin Megadyptes 
antipodes, all penguin species breed colonially [73]. In these colonies, birds often breed in high densities, for instance, 1.4 nest. $\mathrm{m}^{-2}$ in Adélie penguins [74] and up to 10 birds. $\mathrm{m}^{-2}$ in huddling emperor penguins $[16,75]$, which highly increases the level of social stimulations and interactions [76]. High densities of breeding birds have led to the evolution of a varied and complex repertoire of visual and vocal displays (e.g. [77]). As penguins are widely distributed in the Southern hemisphere, from the Equator to the Antarctic continent, they are submitted to various ecological constraints that will impact the timing of reproduction. For example, for a high latitude species such as the emperor penguin, two proximate factors controlling the onset of breeding are exogenous factors such as day-length $[1,78]$ and the peak of ocean productivity preceding breeding [79]. For the equatorial Galápagos penguin, the onset of breeding is closely linked to mean sea surface temperature [70]. Therefore, because of the variety of environments where penguins live, the examination of the breeding cycle observed across the Sphenisciformes order can give some insights about how environmental conditions can shape a variety of reproductive strategies. The different aspects of the biology of penguins are relatively sparse in the literature although some books attempted to gather these data (e.g. $[11,12,80,81])$. Therefore, the aim of the present study is to provide researchers working on seabirds with a concise and clear overview of the breeding cycle of the 18 penguin species.

In this review, the breeding cycle of penguins was divided into three stages: (1) the pairing period, when breeders come ashore for courtship and mating, (2) the incubation period, when mates generally take turns to incubate the egg(s), and (3) the rearing period, from chick(s) guard to fledging. We defined the courtship period as the shortest period of time between the early arrival of both sexes on the reproductive site and the laying of the first egg because females may occasionally go 
126 to sea before the full clutch is completed (e.g. gentoo penguins, [11], magellanic 127 penguins Spheniscus magellanicus, [82]). The body mass of the adult birds 128 considered was the mean body mass at the onset of the breeding period, i.e. at their 129 arrival on the breeding site.

\section{Geographical range and population status}

132 Penguins are widely distributed in the Southern hemisphere, mainly between 45 and

$13360^{\circ} \mathrm{S}$ (Fig. 2) and four penguin species are endemic to their breeding island:

134 Fiordland (or crested) Eudyptes pachyrhynchus, Galápagos, royal Eudyptes schlegeli

135 and Snares penguins. Penguins represent roughly $90 \%$ of bird biomass in the

136 Southern Ocean [12] and Pygoscelis species (chinstrap P. antarctica, Adélie and gentoo penguins) represent $70 \%$ of Antarctic avian biomass [83]. Penguins feed in pelagic cold waters, rich in zooplankton and biomass, where they consume approximately two millions tons of carbon per year [84]. However, they occupy a wide variety of habitats while breeding on land, ranging from the burrows in the volcanic

141 rocks of the hot Galápagos Islands (Galápagos penguin), the bushes of south

142 Australia and New-Zealand (little penguin), to the ice of the border of the Antarctic continent (emperor, Adélie, chinstrap and gentoo penguins). This results in a high variability in all aspects of the breeding biology of the different penguins' species (Fig. 1A). While most species breed annually, some species, such as African (or

146 jackass) and Galápagos penguins, can have no distinct annual breeding season (i.e.

147 breeding season occurs year-round). Because of the short Antarctic summer, 148 breeding is generally much synchronised in Antarctic species, but in temperate 149 climates, it can be spread over a longer period of time. For example, the timing of 150 egg-laying greatly varies between years for the little penguin [85]. 
152 temporarily unpredictable. Penguins make use of wide geographical areas in the 153 ocean while foraging and during migrations. Penguins, which are central place 154 foragers during the breeding season, are thus particularly sensitive to variations in 155 ecosystem structure and processes. Of the 18 penguins' species, 13 are considered

156 endangered or threatened (Table 1) and some species are now at their lowest 157 recorded populations: Galápagos, yellow-eyed, and Fiordland have less than 158 3,000 pairs; Humboldt (Spheniscus humboldti), Snares and African have less than 15930,000 pairs. Even abundant species like the macaroni (Eudyptes chrysolophus) and 160 the rockhopper (Eudyptes chrysocome and E. moseleyi) are in steep decline [86]. On

161 the contrary, the global population trend is stable for Snares and Adélie penguins [86] 162 or is increasing for gentoo $[87,88]$ and king penguins [86]. The status of the emperor 163 penguin might change in the near future. Indeed, thanks to satellite images showing 164 faecal stains on ice, Fretwell and Trathan [89] discovered 10 new emperor penguins 165 colonies [90]. Around $80 \%$ of the threatened species live on islands, increasing their 166 vulnerability to threats such as introduced predators. Many penguin species face the 167 same four key threats: global climate change, marine pollution, fisheries 168 mismanagement, and introduced mammalian predators [91].

170 Relative importance of each phase of the breeding cycle: focus on pairing 171 period

172 Among the 18 penguin species, the duration of the breeding season ranges from 4 to 17315 months (Fig. 1A). It is especially long for the two largest penguins (who need 174 more time for their chick to grow) and particularly for the king penguin Aptenodytes 175 patagonicus. Emperor penguins' cycle lasts 9 months including a 1.5 month pairing 
176 period that is long relative to other penguin species (Fig. 1A; [79]). Indeed, while the 177 courtship period ranges from less than 1 week in little, gentoo, Jackass or African

178 Spheniscus demersus and magellanic penguins, it lasts up to 6 weeks in emperor 179 penguins (Fig. 1A). The ratio courtship-breeding duration accounts for $16 \%$ in 180 emperor penguin (1.5 month vs. 9 months) whereas it accounts for only $3 \%$ in its

181 closest relative, the king penguin (1.5 week vs. 15 months). Considering the long 182 duration of the total breeding cycle in emperor penguins, this ratio is, however, 183 almost of the same magnitude (14 - 18\%) as with other species breeding in 184 Antarctica (Adélie, chinstrap and gentoo penguins; Fig. 1B). Contrary to the emperor 185 penguin, the king penguin does not exhibit a long courtship period but an extended 186 chick-rearing period (84\% of the breeding cycle while it represents about $57 \%$ in 187 other species; Fig. 1B). In king penguins, breeding overlaps two years (Fig. 1A) which consequently results in a maximum of two chicks being reared within a three year period.

\section{Fidelity, sex ratio, and courtship}

192 All penguins are monogamous, mating with only a single partner each year. In addition, most penguin species are territorial and show a moderate to high interannual fidelity in breeding (59 - $89 \%$; Table 1), partners reuniting from year to year on their nest site. Pair bonds can therefore be long-lasting (Table 1) with many birds returning to meet their previous partners at the same breeding site each year. Two

197 Aptenodytes species and especially the emperor penguin, however, show a low inter198 annual fidelity (15\%; Table 1$)$, due to the fact that they do not use a nest, and 199 incubate their egg on their feet $[92,93]$. Partners cannot therefore reunite themselves 200 from year to year on the nest site and one could hypothesize that these penguins 
201

202

203

204

205

206

207

208

209

210

211

212

213

214

215

216

217

218

219

220

221

222

223

224

225

need more time than other species to find and reunite with their previous mate. King penguins, however, show a low inter-annual fidelity (29\%; Table 1) despite being highly territorial and occupying distinct nest sites. These birds could easily reunite with their partners provided they return on time but it does not seem to be the case for $70 \%$ of them.

A male-biased sex ratio appears to be a characteristic of breeding populations of several penguin species such as yellow-eyed, gentoo, little, Adélie, macaroni penguins [11]. In Adélie and macaroni penguins, males return first [11] to previous year's nest-site to maximize their chances of reuniting with their mates from the previous year. This suggests that the primary "aim" of male penguins returning to the breeding colony would be to retain their old nest-sites and, only secondarily, to reunite with their previous mates. Because in many species there are more males in the population than females, male-male competition for nest-sites, rather than for mates, is an important determinant of breeding opportunity. In contrast, at least for the Pointe Géologie colony (Adélie Land, $140^{\circ} \mathrm{E}-67^{\circ} \mathrm{S}$ ), sex ratio favours female emperor penguins that outnumber males by about $10 \%[31,92-94]$. This might be due to a higher mortality of male breeders after their long winter fast [95]. Because of this unbalanced sex-ratio and because mate fidelity is particularly low in this species, competition between females is high to find a male and the earlier a female returns at the onset of the breeding cycle, the higher the probability she will get a mate [31], and the lower the probability that her previous mate will already be paired with another female. Furthermore, the number of male partners available per unpaired female decreases as time passes. Consequently, an early arrival enhances the likelihood for the females to preserve their breeding status by finding an unpaired mate. Unbalanced sex ratio in emperor penguins probably also explains occurrence 
of polygynous trios (one male with two females) but these groups are temporary, one

227 female usually ejecting the other after a few hours [16,31].

\section{From yolk development to fledging}

The period of yolk development that precedes ovulation is given by the following equation for non-procellariiform seabirds: $\log t=0.396+0.283 \log$ egg mass [96] where t stands for time (day) and egg mass is expressed in grams. Once the yolk is fully developed, it is retained within the ovarian follicle for about 6 days before ovulation [97]. The albumen and shell are then added over about 24 hours, following ovulation. In species with two eggs [98-101], development of the second egg (B-egg) is initiated 4 days after the first one (A-egg). Thus, in order to calculate the time elapsed from yolk formation until egg-laying, we added $7(6+1)$ and 11 days $(4+6+1)$ for the A-egg and the B-egg, respectively (Table 1). Incubation refers to the process by which birds lay their egg(s), and to the

240 development of the embryo within the egg. The most vital factors of incubation are 241 the temperature required for embryo development over a specific period, humidity 242 (which could be problematic in dry environments like the Galápagos Islands or 243 Antarctica), and egg rotation rate [102]. If the air is too dry, the egg will lose too much 244 water, which can make hatching difficult or impossible. As incubation progresses, an 245 avian egg becomes lighter, and the air space within the egg becomes larger owing to 246 the evaporation from the egg. In most penguin species, incubation is divided 247 differently between parents with the male and the female taking turns incubating the 248 egg(s). The emperor penguin represents an exception as in this species, only the 249 male incubates. 
251 relative to their body weight $(2.9 \pm 0.9 \%, n=16$, mean \pm SD, Table 1$)$, and eggs of smaller penguin species are proportionately larger (Table 1). The majority of penguins lays two white eggs (except genus Aptenodytes laying only one egg), weighing from 55 to $445 \mathrm{~g}$ (little and emperor penguins, respectively, Table 1). Within the genus Eudyptes, the second egg or B-egg is $20-78 \%$ larger than the first one (Table 1) and consequently the first chick is smaller than the second one and generally fails to survive [11]. Erect-crested penguins are obligate brood reducers [46] and exhibit the most extreme egg-size dimorphism of any bird: the second egg is up to $100 \%$ the size of the first and is the only one to be incubated. It remains unclear why these birds should lay two eggs but only ever rear one chick. The total time necessary for yolk deposition is proportional to female's body mass [97] but full clutch synthesis has the same duration among the 18 penguin species, ca. 3 weeks (Table 1; $20.6 \pm 0.7$ days, $n=16$, mean $\pm S D$ ). By subtracting the duration of the full clutch completion from the duration of the pairing period, we can report that egg formation begins while females are still at sea (in 13 species), while they arrive at the breeding site (in 1 species), and while they already are on the breeding site (in 3 species; Fig. 3). Among the latter, emperor penguins' egg formation begins late, three weeks after their arrival on the colony. Thus, egg formation is not responsible for the long duration of the pairing period, representing only one half of the courtship duration.

Incubation ranges from ca. 35 to 65 days (Eudyptes and Pygoscelis species, emperor penguins, respectively, Fig. 1B). It is an energetically demanding process, especially in male emperor penguins that can lose up to $45 \%$ of their initial body weight during this time. Some species begin incubation with the first egg, causing the 
275 young to hatch asynchronously; others begin after laying the second egg, thus 276 decreasing hatching asynchrony between siblings [103]. Both parents are involved in parental care. From the moment the egg is hatched, one parent cares for the newly hatched chick(s) while the other forages for food. Penguin chicks are semi-altricial, i.e. they need parental care (food, warmth, protection) before becoming independent. At the start of the rearing period, the chicks either sit on their parents feet (emperor and king penguins) or under their bellies, to be kept warm and dry. Young are guarded (guarding stage) by both parents for varying periods of time before forming crèches. Both parents feed the chicks by regurgitation. Nestlings beg for food by pecking adult's bill and/or by singing. Guarding stage may be affected by environmental conditions [102] and when they are not being protected by the adult, the chicks form crèches to keep warm and stay protected. As the chicks grow, their feeding requirements quickly increase, making it difficult for just one of the parents to obtain enough food. Eventually, the chicks are large enough so that both parents can go to sea to gather food for their chick simultaneously. When parental provisioning is low, alloparental feeding (feeding of offspring by adults other than their own parents) sometimes occurred in little [104], emperor [105], king [106] and Adélie penguins [74]. In most species the chicks gather together in crèches to provide protection both from predators and from the elements. In some species, such as king penguins, crèches can be large with many hundreds of chicks tightly packed together. In other species such as African penguins, the crèches are smaller (with up to 10 chicks coming together) and less dense. Age at fledging ranges from one to eleven months (Fig. 1A) and fledglings are a bit smaller and lighter than adults, except in emperor penguins for which body mass of fledglings is about half of adults' [16]. While they are still on their breeding 
grounds, chicks have to moult to adorn themselves with a waterproof plumage, which will allow them in turn to go hunting offshore and acquire their food independently. Adults also have to moult like other birds and all penguins replace their feathers each year on their breeding grounds, except for the emperor penguins for which moulting often takes place far away from their breeding grounds [107-109]. Although other birds lose some feathers individually at a time and replace them over a few months, penguin moulting is fast, taking only two (e.g. Pygoscelis antarctica, [110]) to five weeks (e.g. genus Aptenodytes, $[16,111,112])$. Moulting is extremely important to penguins as they need to maintain their feathers in perfect condition at all times to insulate their body from environmental conditions at sea or on land. Adults generally moult after the breeding season. Once their chicks have moulted into their own 311 juvenile plumage the adults return to sea for a few weeks to build up their own fat reserves and then come back ashore to moult. During the moult, penguins are no longer waterproof and cannot enter the sea, they can lose up to $50 \%$ of their body mass, they are not well insulated and they are vulnerable to predation. Therefore, 315 this is a critical period of time for penguins during which they have to face the 316 elements and starve until their new set of feathers is ready.

\section{Genus Aptenodytes}

319 Birds of the genus Aptenodytes (A. forsteri and A. patagonicus) are bigger and taller 320 than other penguin species (Table 1). They do not build a nest and only lay one large 321 egg (on average 445 and $307 \mathrm{~g}$, respectively; Table 1), which is kept on the top of 322 the incubating parents' feet at least for 54 days (Fig. 1B). As for other penguins, 323 parents recognise their chick by voice and young also recognise parents by call [11]. 
The breeding cycle of the genus Aptenodytes largely differs from the breeding cycle of most of the other penguin species. In most penguin species, it takes from 8 to 15 weeks to raise a chick to the juvenile stage (Fig. 1B) but it can take 10 to 13 months for king penguins to fledge their chick [18]. Because of this long chickrearing period, king penguins only produce two chicks every three years. As a result, 12-month-old chicks cohabit with incubating birds in king penguin colonies. Every 330 year, emperor penguins manage to raise their large chicks more quickly (five months), using a different strategy. Indeed the chicks moult into juvenile plumage while they are still much smaller than their parents. The juveniles then continue to grow out at sea.

The emperor penguin also seems to be an exception among penguins as they begin their breeding cycle when other Antarctic birds have finished theirs. Each year, from late December to March (i.e. late summer), emperor penguins disperse into the oceans, travelling and foraging into the waters surrounding the Antarctic continent $[109,113]$. In March-April, as winter approaches and fast-ice extent grows, all mature emperor penguins move south towards their colonial breeding areas at the border of 340 the Antarctic continent. The breeding cycle of emperors stands in contrast with that of 341 other penguin species (except for the king penguin) by its long duration and by the 342 fact that it takes place in the midst of the severe Antarctic winter, whereas other 343 penguins breed during the short and milder summer season. Indeed, the emperor 344 penguin is one of the few birds for which gonadal growth is coincident with short 345 days, when birds are still at sea. Gonadal steroids are several fold above basal level 346 at the time of arrival on the breeding area suggesting that environmental cues, 347 especially decreasing daylength, decreasing air temperature, and sea-ice formation, 348 stimulate gonadal development and reproduction [1]. Before breeding, emperor 
penguins forage far away from their breeding grounds $[109,114,115]$. In the Southern

350 Ocean, a period of high productivity occurs during summer, from October to April,

351

352

353

354

355

356

357

358

359

360

361

362

363

364

365

366

367

368

369

370

371

372

373

and is followed by a period of low productivity during winter, from May to September [116-118]. Because emperor penguins breed in winter, they have to anticipate their breeding season by accumulating body reserves during high ocean productivity in the previous summer [79]. To our knowledge, this breeding strategy is unique among animals. Furthermore, emperors breed on sea-ice in a few favourable zones that may be a hundred kilometres distant from the open sea or polynias where they exclusively feed [119]. As a consequence of the distance from the feeding grounds, and because breeding activity competes with feeding, female and male emperors fast for as long as 1.5 and 4 months, respectively [16,31]. For females, the breeding fast comprises only the courtship period, since they leave their single egg to their mate as soon as it is laid and then go back to sea for building up their reserves. For males, the period of fasting includes the courtship and the whole incubation period. To face the austral winter, emperor penguins have to exploit in an optimal way their limited body fuels in order to succeed in their breeding $[16,120,121]$. This is possible only thanks to their huddling behaviour, which allows them to decrease energy expenditure $[120,121]$.

\section{Which environmental changes might affect the breeding cycle of the different} penguin' species?

The Earth's climate is undergoing rapid warming which is driving shifts in the distribution and phenology of many plants and animals [122,123]. Among animals, penguins are adapted to live in extreme environments (Fig. 2), but, because each species is restricted to a limited latitudinal range (Table 1), they can be highly sensitive to climate change [124]. Environmental changes are not uniform across 
374 regions, with resource increasing in the subantarctic areas and decreasing in 375 Antarctica [123]. Quantifying changes in breeding phenology is important for 376 understanding how populations respond to these changes, especially those resulting 377 from human activities [123].

378 Climatic changes and resource availability: Detecting and predicting how 379 populations respond to environmental variability are crucial challenges in 380 management and conservation research. This is particularly true for populations at 381 high latitudes, many of which demonstrate changes in population dynamics 382 associated with global warming [125]. Some seabird populations of the Southern 383 Ocean have been responding to climate change for the last three decades and 384 demographic models suggest that projected warming will cause dramatic population 385 changes over the next century [114]. In the Antarctic ecosystem, population 386 dynamics of top predators like penguins may yield important information about how the environment is changing [126]. The phenotypic plasticity of penguins may allow them to continue to exploit their transformed ecological niche and maintain their current distributional ranges. For instance, penguins may vary the timing of breeding 390 in response to changes in environmental conditions [127]. However, paleoecological 391 records suggest that penguins are more likely to respond by dispersal rather than adaptation [124]. Thus shift in species distribution is likely to be one of the major possible adaptations to changing environmental conditions [114]. This is exemplified by the distributional range of chinstrap [124,126,128], gentoo and Adélie penguins $395[124,129-130]$ that has shifted southwards around the Antarctic Peninsula. However, as each species is limited to a specific latitudinal range, a latitudinal 397 shift may be very limited. Thus, emperor penguins' colonies north of $70^{\circ} \mathrm{S}$ are 398 projected to decrease or disappear, and limited growth might occur south of $73^{\circ} \mathrm{S}$ 
[131]. These population trends are likely to be related to sea ice conditions [132]. For

400 example, at Pointe Géologie (Adélie Land), distance to the fast ice edge and its 401 extent are major determinants of emperor penguin breeding success [132]. 402 Therefore, the increased frequency of warm events associated with projected 403 decreases in sea ice extent is likely to reduce population viability $[133,134]$.

404 Other physical factors than sea-ice can also affect penguin populations. For 405 instance, sea surface temperature consistently drives the foraging behaviour of king 406 penguins, and, according to climate models, the projected warming of surface waters 407 could lead to a gradual southward shift of their more profitable foraging zones [114]. 408 Such a shift would negatively affect the king penguin population, unless penguins 409 develop alternative foraging strategies [114] as to modify their timing of breeding $410 \quad[127]$.

The Antarctic Peninsula is among the fastest-warming areas on the Earth, with $5-6^{\circ} \mathrm{C}$ increases in mean winter air temperatures and associated decreases in winter sea-ice cover [135]. These perturbations have affected the ecosystem profoundly 414 [135]. To respond to these climatic changes, varying the timing of reproduction in 415 response to local environmental conditions is a key factor influencing reproductive success [127]. For example, clutch initiation and hatching dates of royal, Adélie and gentoo penguins occur earlier with warmer temperatures $[123,127]$. However, these behavioural adjustments may not be sufficient to prevent populations from declining.

419 The "sea-ice hypothesis" proposing that ice-obligate species directly decline because 420 of sea-ice reduction, does not appear to be sufficient to explain why populations of 421 both ice-loving and ice-avoiding penguins have declined significantly [135]. Some 422 researchers argue in favour of an alternative, more robust hypothesis, that attributes 423 both increases and decreases in penguin populations to changes in the abundance 
424 of their main prey, Antarctic krill [135]. Indeed, decline of chinstrap penguin

425 populations has been suggested as being related to climate change through a 426 reduction in sea-ice extent during winter and a consequent decline in the abundance 427 of krill in summer during the breeding season [126].

428 Climate changes can also have more subtle consequences on the foraging 429 behaviour of penguins. For instance, mixed water regimes resulting from storms, 430 result in the dispersion of prey items in the water column. This lack of prey 431 stratification has been described as resulting in reduced foraging efficiency and poor 432 breeding success in the little penguin [136]. Mixed water regimes are currently 433 unusual during the breeding period of little penguins, but are expected to become 434 more frequent due to climate change and may therefore represent an important 435 threat for this species [136].

436 Tourism: Antarctica now fuels one of the fastest growing tourism markets in the 437 world with over 30,000 visitors annually travelling to the continent [137]. Increasing 438 ecotourism activity has led to concerns about the effects of ecotourism on wildlife 439 populations. While some species of penguins habituate to human visits, others 440 exhibit negative effects due to disturbance [138]. Behavioural, physiological, and 441 reproductive parameters might thereby be affected. For example, human presence at 442 the nest site is physiologically stressful for breeding Magellanic penguins that are not 443 accustomed to seeing humans [139]. Indeed, Magellanic penguins in visited areas 444 have higher corticosterone stress responses than penguins in undisturbed areas $445[138,140]$. Moreover, birds exposed to moderate levels of disturbance do not show 446 evidence of habituation over a period of a few years [139]. However, penguins may 447 habituate to Humans, as birds that have been exposed to very high levels of human 448 visitation do not respond anymore to human presence as a stressor. Furthermore, 
Magellanic chicks from tourist-visited colonies do not flee anymore when approached

450 by humans [140], and breeding success is not affected by visitation levels in this 451 species [138]. However, penguin species differ in their sensitivity to human presence.

452 For instance, in contrast to Magellanic and Adélie penguins, yellow-eyed and gentoo 453 penguins show significantly lower breeding success at sites exposed to unregulated 454 tourism compared to areas visited infrequently $[130,141]$. This may be attributed to 455 the presence of people on beaches that delays post-foraging landing by penguins 456 provisioning their chicks, which may in turn affect the amount of food delivered to the 457 young. Indeed, yellow-eyed chicks from nesting areas with high numbers of tourists 458 have significantly lower fledging weights than chicks from areas with no tourist 459 visitors [142]. Taking into account that the probability of survival is positively 460 associated with mass at fledging, lower fledging weights may have long-term population consequences [142].

\section{Conclusion}

The present article shows that breeding strategies are diverse and differ between penguin species. However, breeding behaviour can also exhibit some plasticity within each penguin species and particularly when environmental conditions vary (e.g. [102]). More studies simultaneously conducted (1) in several penguin species breeding in the same location and (2)

(2) on the same species in different

469 locations/environmental conditions would be useful to highlight how environmental 470 conditions influence breeding strategies in penguins and how penguins can adapt to 471 environmental perturbations.

472 Many penguin species face the same threats [91]. Marine and coastal 473 ecosystems are undergoing unprecedented alterations in their processes and 
474 structure. Penguins are sensitive species impacted by these phenomena. As top 475 predators, they are key constituents of marine ecosystems, and are indicators of the 476 oceanic and coastal ecosystem health. Larger scale ecosystem-based conservation 477 planning and more focused local efforts are needed for the successful conservation 478 of many penguin species.

\section{Acknowledgements}

481 We thank Drs C.-A. Bost, A. Chiaradia, P. Dee Boersma, C. Hull, M. Massaro, K. 482 Pütz, Y. Ropert-Coudert, A. Steinfurth and P. Trathan for providing data on the 483 different species of penguins. We also thank Dr. S. Gallon for her help in revising the 484 language. The manuscript benefited from critical comments by anonymous 485 reviewers.

\section{References}

[1] R. Groscolas, M. Jallageas, A. Goldsmith, I. Assenmacher, The endocrine control of reproduction and moult in male and female Emperor (Aptenodytes forsteri) and Adélie (Pygoscelis adeliae) penguins. I. Annual changes in plasma levels of gonadal steroids and luteinizing hormone, Gen. Comp. Endoc. 62 (1986) 43-53. especially for migrants, Ardea 94 (2006) 305-322.

494 [3] E.L. Charnov, J.R. Krebs, On clutch size and fitness. Ibis 116 (1974) 217-219.

495 [4] D. Lack, Population studies of birds, Oxford University Press, Oxford, 1966.

496 [5] M.M. Lambrechts, J. Blondel, M. Maistre, P. Perret, A single response mechanism 497 is responsible for evolutionary adaptative variation in a bird's laying date, P. Natl. 498 Acad. Sci. USA 94 (1997) 5153-5155. 
[6] P.J. Sharp, Strategies in avian breeding cycles, Anim. Reprod. Sci. 42 (1996)

500

501

502

503

504

505

506

507

508

509

510

511

512

513

514

515

516

517

518

519

520

521

522

505-513.

[7] P. Monaghan, J.D. Uttley, M.D. Burns, Effect of changes in food availability on reproductive effort in Arctic Terns Sterna paradisaea, Ardea 80 (1992) 71-81.

[8] K. Camphuysen, Post-fledging dispersal of Common Guillemots Uria aalge guarding chicks in the North Sea: The effect of predator presence and prey availability at sea, Ardea 90 (2002) 103.119.

[9] G.M. Liddle, Interannual variation in the breeding biology of the Antarctic prion Pachyptila desolata at Bird Island, South Georgia, J. Zool. 234 (1994) 125-139.

[10] J.P. Croxall, P.A. Prince, Food, feeding ecology and ecological segregation of seabirds at South Georgia, Biol. J. Linn. Soc. 1 (1980) 103-131.

[11] S. Marchant, P.J. Higgins, Handbook of Australian, New Zealand and Antarctic Birds, Volume 1, M. Sharp, Melbourne, 1990.

[12] T.D. Williams, The Penguins: Sphenicidae, New York, Oxford University Press, 1995.

[13] P. Jouventin, R.J. Cuthbert, R. Ottvall, Genetic isolation and divergence in sexual traits: evidence for the northern rockhopper penguin Eudyptes moseleyi being a sibling species, Mol. Ecol. 15 (2006) 3413-3423.

[14] R.W. Rand, The biology of guano-producing seabirds: the distribution, abundance and feeding habits of the Cape penguin, Spheniscus demersus, off the south western coast of the Cape Province, Investig. Rep. 41 (1960) 1-28.

[15] R. Groscolas, Changes in plasma lipids during breeding, moulting and starvation in male and female emperor penguins (Aptenodytes forsteri), Physiol. Zool. 55 (1982) 45-55. 
523 [16] J. Prévost, Ecologie du manchot empereur, Expéditions polaires françaises, 524 Paris, Hermann Press, 1961.

525 [17] A. Barrat, Quelques aspects de la biologie et de l'écologie du manchot royal 526 (Aptenodytes patagonicus) des lles Crozet, C.N.F.R.A. 40 (1976) 9-51.

527 [18] B. Stonehouse, The king penguin Aptenodytes patagonicus of South Georgia I. 528 Breeding behaviour and development, Sci. Rep. Falkland Islands Dependency 529 Survey 23 (1960) 1-81.

530 [19] C.L. Hull, M. Hindell, K. Le Mar, P. Scofield, J. Wilson, M.A. Lea, The breeding 531 biology and factors affecting reproductive success in rockhopper penguin Eudyptes 532 chrysocome at Macquarie Island, Polar Biol. 27 (2004) 711-720.

533 [20] J. Warham, The rockhopper penguin, Eudyptes chrysocome, at Macquarie 534 Island, Auk 80 (1963) 229-256.

535 [21] J.O. Murie, L.S. Davis, I.G. McLean, Identifying the sex of Fiorland crested 536 penguins by morphometric characters, Notornis 38 (1991) 233-238.

537 [22] J. Warham, The Fiordland crested penguin Eudyptes pachyrhynchus, Ibis 116 538 (1974) 1-27.

539 [23] J. Warham, The breeding biology and behaviour of the Snares crested penguin, 540 J. Roy. Soc. New Zeal. 4 (1974) 63-108.

541 [24] R. Carrick, Population ecology of the Australian black-baked magpie, royal 542 penguin, and silver gull. Population ecology of migratory birds, a symposium. U.S. 543 Depart. Interior Wildlife Research Rep. 2 (1972) 41-98.

544 [25] J. Warham, Aspects of the biology of the erect-crested penguin, Eudyptes 545 sclateri, Ardea 60 (1972) 145-184. 
546 [26] F.C. Kinsky, R.A. Falla, A subspecific revision of the Australian blue penguin 547 (Eudyptula minor) in the New Zealand area, Rec. Natl. Museum New Zeal. 1 (1976) $548 \quad 105-126$.

549 [27] P.J. Moore, Breeding biology of the yellow-eyed penguin Megadyptes antipodes 550 on Campbell Island, Emu 92 (1993) 157-162.

551 [28] D.G. Ainley, W.B. Emison, Sexual size dimorphism in Adélie penguins. Ibis 114 552 (1972) 267-271.

553 [29] W.Z. Trivelpiece, S.G. Trivelpiece, Courtship period of Adélie, gentoo and 554 chinstrap penguins, in: L.S. Davis, J.T. Darby (Eds.), Penguin biology. Academic 555 Press, San Diego, 1990, pp. 113-127.

556 [30] P.D. Boersma, D.L. Stokes, P.M. Yorio, Reproductive variability and historical 557 change of Magellanic penguins (Spheniscus magellanicus), in: L.S. Davis, J.T. Darby 558 (Eds.), Penguin biology. Academic Press, San Diego, 1990, pp. 15-43.

559 [31] P. Isenmann, Contribution à l'éthologie et à l'écologie du manchot empereur 560 (Aptenodytes forsteri Gray) à la colonie de Pointe Géologie (Terre Adélie). L'Oiseau 561 et la R.F.O. 41 (1971) 9-64.

562 [32] J.P. Croxall, P.A. Prince, Antarctic seabird and seal monitoring studies, Polar 563 Rec. 19 (1979) 573-595.

564 [33] T.D. Williams, S. Rodwell, Annual variation in return rate, mate and nest-site 565 fidelity in breeding gentoo and macaroni penguins, Condor 94 (1992) 636-645.

566 [34] L.E. Richdale, A population study of penguins, Oxford University Press, Oxford, $567 \quad 1957$.

568 [35] P. Isenmann, E.P. Jouventin, Eco-éthologie du Manchot empereur (Aptenodytes 569 forsteri) et comparaison avec le Manchot Adélie (Pygoscelis adeliae) et le Manchot 570 royal (Aptenodytes patagonica), L'Oiseau et la R.F.O. 40 (1970) 136-159. 
571 [36] T.L. Bucher, G.A., Bartholomew, W.Z. Trivelpiece, N.J. Volkman, Metabolism,

572 growth and activity in Adélie and emperor penguin embryos, Auk 103 (1986) 485-

573493.

574 [37] R. Guillard, J. Prévost, Observations écologiques à la colonie de manchots 575 empereurs de Pointe Géologie (Terre Adélie) en 1963, L’Oiseau et la R.F.O. 34 $576 \quad$ (1964) 33-51.

577 [38] J.L. Mougin, Observations écologiques à la colonie de Pointe Géologie en 1964, 578 L'Oiseau et la R.F.O. 36 (1966) 166-226.

579 [39] R.W. Rand, Note on the birds of Marion Island, Ibis 96 (1954) 173-206.

580 [40] M. Poisbleau, L. Demongin, I.J. Strange, H. Otley, P. Quillfeldt, Aspects of the 581 breeding biology of the southern rockhopper penguin Eudyptes c. chrysocome and 582 new consideration on the intrinsic capacity of the A-egg, Polar Biol. 31 (2008) 925583932

584 [41] J.C. Stahl, P. Derenne, P. Jouventin, J.L. Mougin, L. Teulières, H. Weimerskirch, 585 Le cycle reproducteur des gorfous de l'archipel Crozet: Eudyptes chrysolophus, le 586 gorfou macaroni et Eudyptes chrysochome, le gorfou sauteur, L'Oiseau et la R.F.O. 58755 (1985) 27-43.

588 [42] J. Warham, Breeding season and sexual dimorphism in rockhopper penguins, 589 Auk 89 (1972) 86-105.

590 [43] A.J. Williams, Offspring reduction in macaroni and rockhopper penguins, Auk 97 591 (1980) 754-759.

592 [44] A.M. Gwynn, The egg-laying and incubation periods of rockhopper, macaroni 593 and gentoo penguins, ANARE Report B 1 (1953) 1-29. 
594 [45] T.D. Williams, J.P. Croxall, Annual variation in breeding biology of macaroni 595 penguins, Eudyptes chrysolophus, at Bird Island, South Georgia, J. Zool. 223 (1991) $596 \quad$ 189-202.

597 [46] C.C. St. Clair, Incubation behaviour, brood patch formation and obligate brood 598 reduction in Fiorland crested penguins, Behav. Ecol. Sociobiol. 31 (1992) 409-416.

599 [47] C.M. Miskelly, P.W. Carey, Egg laying and egg loss by erect-crested penguin, in: 600 University of Canterbury Antipodes Island Expedition Report. University of 601 Canterbury, New Zealand, 1990, pp. 2-11.

602 [48] L.E. Richdale, The erect-crested penguin (Eudyptes sclateri), Emu 41 (1941) 2560353.

604 [49] L.E. Richdale, Further notes on the erect-crested penguin, Emu 49 (1950) 153605166.

606 [50] G.S. Lishman, The food and feeding ecology of Adélie penguins (Pygoscelis 607 adeliae) and chinstrap penguins (Pygoscelis antarctica) at Signy Island, South 608 Orkney Islands, J. Zool. 205 (1985) 245-263.

609 [51] B. Reid, The Adélie penguin (Pygoscelis adeliae) egg, New Zeal. J. Sci. 8 (1965) $610 \quad 503-514$.

611 [52] R.H. Taylor, The Adélie penguin, Pygoscelis adeliae, at Cape Royds, Antarctica, 612 Ibis 104 (1962) 176-204.

613 [53] G.S. Lishman, The comparative breeding biology of Adélie and chinstrap 614 penguins, Pygoscelis adeliae and Pygoscelis antarctica, at Signy Island, South 615 Orkney Islands, Ibis 127 (1985) 84-99.

616 [54] C.A. Bost, P. Jouventin, The breeding performance of the gentoo penguin 617 Pygoscelis papua at the northern edge of its range, Ibis 133 (1991) 14-25. 
618 [55] A.J. Williams, Aspects of the breeding biology of the gentoo penguin Pygoscelis papua, Le Gerfault 70 (1980) 283-295.

620 [56] A.J. Williams, J. Cooper, Aspects of the breeding biology of the jackass penguin, 621 Spheniscus demersus, Proceedings of the Fifth Pan-African Ornithological 622 Conference, 1984, pp. 841-853.

623 [57] J. Boswall, D. Maclver, The Magellanic penguin Spheniscus magellanicus, in: B. 624 Stonehouse (Ed.), The biology of penguins. Macmillan, London, 1975, pp. 271-305.

625 [58] J.C. Banks, A.D. Mitchell, J.R. Waas, A.M. Paterson, An unexpected pattern of 626 molecular divergence within the blue penguin (Eudyptula minor) complex, Notornis $627 \quad 49$ (2002) 29-38.

628 [59] H. Weimerskirch, J.C. Stahl, P. Jouventin, The breeding biology and population 629 dynamics of king penguins Aptenodytes patagonica on the Crozet Islands, Ibis 134 $630 \quad$ (1992) 107-117.

631 [60] J.L. Mougin, La ponte du gorfou macaroni, Eudyptes chrysolophus, de l'Archipel 632 Crozet, L'Oiseau et la R.F.O. 54 (1984) 281-291.

633 [61] J. Warham, Aspects of breeding behaviour in the royal penguin, Eudyptes 634 chrysolophus schlegeli, Notornis 18 (1971) 91-115.

635 [62] A.F. Chiaradia, K.R. Kerry, Daily nest attendance and breeding performance in 636 the little penguin Eudyptula minor at Phillip Island, Australia, Mar. Ornithol. 27 (1999) $637 \quad 13-20$.

638 [63] N.J. Adams, Embryonic metabolism, energy budgets and cost of production of 639 king Aptenodytes patagonicus and gentoo Pygoscelis papua penguin eggs, Comp. 640 Biochem. Phys. A 101 (1992) 497-503.

641 [64] P. Dann, J.M. Cullen, Survival, patterns of reproduction and lifetime reproductive 642 output in little blue penguins (Eudyptula minor) on Phillip Island, Victoria, Australia, 
643 in: L.S. Davis, J.T. Darby (Eds.), Penguin biology. Academic Press, San Diego, 1990, 644 pp. 63-84.

645 [65] A. Kemp, P. Dann, Egg size, incubation periods and hatching success of Little 646 Penguins Eudyptula minor, Emu 101 (2001) 249-253.

647 [66] A. Kato, A. Yoshioka, K. Sato, Foraging behavior of Adélie penguins during 648 incubation period in Lützow-Holm Bay, Polar Biol. 32 (2009) 181-186.

649 [67] W.J.L. Sladen, The Pygoscelis penguins. 1. Methods of study. 2. The Adélie 650 penguin, Falkland Islands Dependancy Survey Sci. Rep. 17 (1958) 1-97.

651 [68] B. Despin, Note préliminaire sur le manchot papou Pygoscelis papua de l'île de 652 la Possession (archipel Crozet), L'Oiseau et la R.F.O. 42 (1972) 69-83.

653 [69] A. Lescroël, C. Bajzak, C.A. Bost, Breeding ecology of the gentoo penguin 654 Pygoscelis papua at Kerguelen Archipelago, Polar Biol. 32 (2009) 1495-1505.

655 [70] P.D. Boersma, Breeding patterns of Galápagos penguins as an indicator of 656 oceanographic conditions, Science 200 (1978) 1481-1483.

657 [71] A. Chiaradia, I.C.T. Nisbet, Plasticity in parental provisioning and chick growth in 658 Little Penguins Eudyptula minor in years of high and low breeding success, Ardea 94 $659 \quad$ (206) 257-270.

660 [72] F.H. Vargas, S. Harrison, S. Rea, D.W. Macdonald, Biological effects of El Niño 661 on the Galápagos penguin, Biol. Conserv. 127 (2006) 107-114.

662 [73] J.F. Cockrem, P.J. Seddon, Annual cycle of sex steroids in the yellow-eyed 663 penguin (Megadyptes antipodes) on south-island, New-Zealand, Gen. Comp. Endoc. $66494(1994) 113-121$.

665 [74] M. Beaulieu, A.M. Thierry, Y. Le Maho, Y. Ropert-coudert, A. Ancel, Alloparental 666 feeding in Adélie penguins: why is it uncommon?, J. Ornithol. 150 (2009) 637-643.

667 [75] C. Gilbert, G. Robertson, Y. Le Maho, A. Ancel, How do weather conditions 
668 affect the huddling behaviour of emperor penguins?, Polar Biol. 31 (2008) 163-169.

669 [76] V.A. Viblanc, V. Valette, M. Kauffmann, N. Malosse, R. Groscolas, Coping with

670 social stress: heart rate responses to agonistic interactions in king penguins, Behav.

671 Ecol. 23 (2012) 23 1178-1185

672 [77] T. Aubin, P. Jouventin, How to vocally identify kin in a crowd: the penguin model, 673 Adv. Stud. Behav. 31 (2002) 243-277.

674 [78] R. Groscolas, J. Leloup, The endocrine control of reproduction and molt in male 675 and female Emperor (Aptenodytes forsteri) and Adélie (Pygoscelis adeliae) penguins.

676 II. Annual changes in plasma levels of thyroxine and triiodothyronine. Gen. Comp. $677 \quad$ Endoc. 63 (1986) 264-274.

678 [79] A. Ancel, C. Gilbert, M. Beaulieu, The long engagement of the emperor penguin, 679 Polar Biol. (2013, in press).

680 [80] P. Dann, I. Norman, P. Reilly, The Penguins: Ecology and Management, Dann, 681 Norman, Reilly, Australia, 1995.

682 [81] P. Reilly, Penguins of the World, S. Dobney, Oxford University Press, Australia, 6831994.

684 [82] P. Yorio, P.D. Boersma, Causes of nest desertion during incubation in the 685 magellanic penguin (Spheniscus-magellanicus), Condor 96 (1994) 1076-1083. [83] W.Z. Trivelpiece, S.G. Trivelpiece, N.J. Volkman, Ecological segregation of Adélie, gentoo and chinstrap penguins at King George Island, Antarctica, Ecology 68 $688 \quad$ (1987) 351-361.

689 [84] E.J. Woehler, Consumption of Southern Ocean marine resources by penguins, 690 in: P. Dann, I. Norman, P. Reilly (Eds.), The penguins: Ecology and Management. 691 Surrey Beatty \& Sons Pty Limited, Chipping Norton, 1995, pp. 266-294. 
692 [85] S. Robinson, A. Chiaradia, M.A. Hindell, The effect of body condition on the 693 timing and success of breeding in Little Penguins Eudyptula minor, Ibis 147 (2005) 694 483-489.

695 [86] IUCN 2012, IUCN Red List of Threatened Species, Version 2012.2. $696<$ <ww.iucnredlist.org $>$.

697 [87] A.P. Clausen, N. Huin, Status and numerical trends of King, Gentoo, and 698 Rockhopper Penguins breeding in the Falkland Islands, Waterbirds 26 (2003) 389699402.

700 [88] M.I. Ghys, A.R. Rey, A. Schiavini, Population Trend and Breeding Biology of 701 Gentoo Penguin in Martillo Island, Tierra Del Fuego, Argentina, Waterbirds 31 (2008) $702 \quad 625-631$.

703 [89] P.T. Fretwell, P.N. Trathan, Penguins from space: faecal stains reveal the 704 location of emperor penguin colonies, Global Ecol. Biogeogr. 18 (2009) 1-10.

705 [90] P.T. Fretwell, M.A. LaRue, P. Morin, G.L. Kooyman, B. Wienecke, N. Ratcliffe, 706 A.J. Fox, A.H. Fleming, C. Porter, P.N. Trathan, An emperor penguin population 707 estimate: the first global, synoptic survey of a species from space. PLoS One 7 708 (2012): e33751.

709 [91] C. Barbraud, V. Rolland, S. Jenouvrier, M. Nevoux, K. Delord, H. Weimerskirch, 710 Effects of climate change and fisheries bycatch on Southern Ocean seabirds: a 711 review, Mar. Ecol.-Prog. Ser. 454 (2012) 285-307.

712 [92] J. Bried, F. Jiguet, P. Jouventin, Why do Aptenodytes penguins have high 713 divorce rates?, Auk 116 (1999) 504-512.

714 [93] P. Jouventin, Comportement et structure sociale chez le manchot empereur, La 715 Terre et la Vie 25 (1971) 510-586. 
[94] S. Jenouvrier, C. Barbraud, H. Weimerskirch, Long-term contrasted responses to

717 climate of two Antarctic seabirds species, Ecology 86 (2005) 2889-2903.

718 [95] C. Barbraud, H. Weimerskirch, Emperor penguins and climate change, Nature 719 411 (2001) 183-186.

720 [96] L.B. Astheimer, C.R. Grau, A comparison of yolk growth rates in seabird eggs, 721 Ibis 132 (1989) 380-394.

722 [97] L.B. Astheimer, C.R Grau, The timing and energetic consequences of egg 723 formation in the Adélie penguin, The Condor 87 (1985) 256-268.

724 [98] C.J. Scholten, Choice of nest-site and mate in Humboldt penguins (Spheniscus 725 humboldti), Spheniscid Penguin Newsletter 5 (1992) 3-13.

726 [99] E.B. Spurr, Behaviour of the Adélie penguin chick, Condor 77 (1975) 272-280.

727 [100] A.J. Williams, The clutch size of macaroni and rockhopper penguins, Emu 81 $728 \quad(1981) 87-90$.

729 [101] A.J. Williams, The laying interval and incubation period of rockhopper and 730 macaroni penguins, Ostrich 52 (1981) 226-229.

731 [102] M. Beaulieu, A. Dervaux, A.M. Thierry, D. Lazin, Y. Le Maho, Y. Ropert732 Coudert, M. Spée, T. Raclot, A. Ancel, When sea-ice clock is ahead of Adélie 733 penguins' clock. Funct. Ecol. 24 (2010) 93-102.

734 [103] J. Moreno, L.M. Carrascal, J.J. Sanz, J.A. Amat, J.J. Cuervo, Hatching 735 asynchrony, sibling hierarchies and brood reduction in the chinstrap penguin 736 Pygoscelis Antarctica, Polar Biol. 14 (1994) 21-30.

737 [104] B.C. Wienecke, Adoption of chicks by Little Penguins Eudyptula minor on 738 Penguin Island, Western Australia, Emu 95 (1995) 119-122.

739 [105] P. Jouventin, C. Barbraud, M. Rubin, Adoption in the emperor penguin, 740 Aptenodytes forsteri, Anim. Behav. 50 (1995) 1023-1029. 
741 [106] N. Lecomte, G. Kuntz, N. Lambert, J.P. Gendner, Y. Handrich, Y. Le Maho, 742 C.A. Bost, Alloparental feeding in the king penguin, Anim. Behav. 71 (2006) 457-462.

743 [107] G.L. Kooyman, E.C. Hunke, S.F. Ackley, R.P. Van Dam, G. Robertson, Moult of 744 the emperor penguin: travel, location, and habitat selection, Mar. Ecol.-Prog. Ser. $745204(2000)$ 269-277.

746 [108] B. Wienecke, R. Kirkwood, G. Robertson, Pre-moult foraging trips and moult 747 locations of Emperor penguins at the Mawson Coast, Polar Biol. 27 (2004) 83-91.

748 [109] I. Zimmer, R.P. Wilson, C. Gilbert, M. Beaulieu, A. Ancel, J. Plötz, Foraging 749 movements of emperor penguins at Pointe Géologie, Antarctica, Polar Biol. 31 $750 \quad$ (2008) 229-243.

751 [110] D.G. Ainley, R.C. Wood, W.L.J. Sladen, Bird life at Cape Crozier, Ross Island, 752 Wilson Bulletin 90 (1978) 492-510.

753 [111] R. Groscolas, Study of molt fasting followed by an experimental forced fasting 754 in emperor penguin Aptenodytes forsteri - relationship between feather growth, body755 weight loss, body-temperature and plasma fuel levels, Comp. Biochem. Phys. A 61 756 (1978) 287-295.

757 [112] Y. Le Maho, P. Delclitte, J. Chatonnet, Thermoregulation in fasting emperor 758 penguins under natural conditions, Am. J. Physiol. 231 (1976) 913-922.

759 [113] G.L. Kooyman, T.G. Kooyman, M. Horning, C.A. Kooyman, Penguin dispersal 760 after fledging, Nature 383 (1996) 397.

761 [114] C. Peron, H. Weimerskirch, C.A. Bost, Projected poleward shift of king 762 penguins' (Aptenodytes patagonicus) foraging range at the Crozet Islands, southern 763 Indian Ocean, P. Roy. Soc. B-Biol. Sci 279 (2012) 2515-2523. 
764 [115] A. Scheffer, C.A. Bost, P.N. Trathan, Frontal zones, temperature gradient and 765 depth characterize the foraging habitat of king penguins at South Georgia, Mar. 766 Ecol.-Prog. Ser. 465 (2012) 281-297.

767 [116] P. Foxton, The distribution of the standing crop of zooplankton in the southern 768 ocean, Disc. Rep. 28 (1956) 191-236.

769 [117] T.J. Hart, Phytoplancton periodicity in Antarctic surface waters. Disc. Rep. 21 $770 \quad$ (1942) 261-356.

771 [118] E.E. Kopczyńska, N. Savoye, F. Dehairs, D. Cardinal, M. Elskens, Spring 772 phytoplankton assemblages in the Southern Ocean between Australia and 773 Antarctica, Polar Biol. 31 (2007) 77-88.

774 [119] A. Ancel, G.L. Kooyman, P.J. Ponganis, J.P. Gendner, J. Lignon, X Mestre, N. 775 Huin, P.H. Thorson, P. Robisson, Y. Le Maho, Foraging behaviour of emperor 776 penguins as a resource detector in winter and summer, Nature 360 (1992) 336-339.

777

778

779

780 781

782

783

784 [120] A. Ancel, H. Visser, Y. Handrich, D. Masman, Y. Le Maho, Y., Energy saving in huddling penguins, Nature 385 (1997) 336-339.

[121] C. Gilbert, Y. Le Maho, M. Perret, A. Ancel, Body temperature changes induced by huddling in breeding male emperor penguins. Am. J. Physiol. Reg. I 292 (2007) R176-R185.

[122] B.B. Hansen, V. Grøtan, R. Aanes, B.-E. Sæther, A. Stien, E. Fuglei, R.A. Ims, N.G. Yoccoz, Å.Ø. Pedersen, Climate Events Synchronize the Dynamics of a Resident Vertebrate Community in the High Arctic, Science 339 (2013) 313-315.

[123] M.A. Hindell, C.J.A. Bradshaw, B.W. Brook, D.A. Fordham, K. Kerry, C. Hull, C.R. McMahon, Long-term breeding phenology shift in royal penguins, Ecol. Evol. 2 (2012) 1563-1571. 
[124] J. Forcada, P.N. Trathan, Penguin responses to climate change in the Southern

789

790

791

792

793

794

795

796

797

798

799

800

801

802

803

804

805

806

807

808

809

810

811

812

Ocean, Global Change Biol. 15 (2009) 1618-1630.

[125] A.M.M. Baylis, A.F. Zuur, P. Brickle, P.A. Pistorius, Climate as a driver of population variability in breeding Gentoo Penguins Pygoscelis papua at the Falkland Islands, Ibis 154 (2012) 30-41.

[126] A. Barbosa, J. Benzal, A. De Leon, J. Moreno, Population decline of chinstrap penguins (Pygoscelis antarctica) on Deception Island, South Shetlands, Antarctica, Polar Biol. 35 (2012) 1453-1457.

[127] J.T. Hinke, M.J. Polito, C.S. Reiss, S.G. Trivelpiece, W.Z. Trivelpiece, Flexible reproductive timing can buffer reproductive success of Pygoscelis spp. penguins in the Antarctic Peninsula region, Mar. Ecol.-Prog. Ser. 454 (2012) 91-104.

[128] H.J. Lynch, J. Heather, R. Naveen, P.N. Trathan, W.F. Fagan, Spatially integrated assessment reveals widespread changes in penguin populations on the Antarctic Peninsula, Ecol. 93 (2012) 1367-1377.

[129] A.R. Carlini, N.R. Coria, M.M. Santos, J. Negrete, M.A. Juares, G.A. Daneri, Responses of Pygoscelis adeliae and P. papua populations to environmental changes at Isla 25 de Mayo (King George Island), Polar Biol. 32 (2009) 1427-1433.

[130] H.J. Lynch, W.F. Fagan, R. Naveen, Population trends and reproductive success at a frequently visited penguin colony on the western Antarctic Peninsula, Polar Biol. 33 (2010) 493-503.

[131] D. Ainley, J. Russell, S. Jenouvrier, E. Woehler, P.O. Lyver, W.R. Fraser, G.L. Kooyman, Antarctic penguin response to habitat change as Earth's troposphere reaches 2 degrees C above preindustrial levels, Ecol. Monogr. 80 (2010) 49-66.

[132] R.A. Massom, K. Hill, C. Barbraud, N. Adams, A. Ancel, L. Emmerson, M.J. Pook, Fast ice distribution in Adélie Land, East Antarctica: interannual variability and 
813 implications for emperor penguins Aptenodytes forsteri, Mar. Ecol.-Prog. Ser. 374 814 (2009) 243-257.

815 [133] S. Jenouvrier, H. Caswell, C. Barbraud, M. Holland, J. Stroeve, H. 816 Weimerskirch, Demographic models and IPCC climate projections predict the decline 817 of an emperor penguin population, P. Natl. Acad. Sci. USA 106 (2009) 1844-1847.

818 [134] S. Jenouvrier, M. Holland, J. Stroeve, C. Barbraud, H. Weimerskirch, M. 819 Serreze, H. Caswell, Effects of climate change on an emperor penguin population: 820 analysis of coupled demographic and climate models, Global Change Biol. 18 (2012) $821 \quad 2756-2770$.

822 [135] W.Z. Trivelpiece, J.T. Hinke, A.K. Miller, C.S. Reiss, S.G. Trivelpiece, G.M. 823 Watters, Variability in krill biomass links harvesting and climate warming to penguin 824 population changes in Antarctica, P. Natl. Acad. Sci. USA 108 (2011) 7625-7628.

825 [136] Y. Ropert-Coudert, A. Kato, A. Chiaradia, Impact of small-scale environmental 826 perturbations on local marine food resources: a case study of a predator, the little 827 penguin, P. Roy. Soc. B-Biol. Sci. 276 (2009) 4105-4109.

828 [137] R.B. Powell, M.T.J. Brownlee, S.R. Kellert, S.H. Ham, From awe to satisfaction: 829 immediate affective responses to the Antarctic tourism experience, Polar Rec. 48 $830 \quad$ (2012) 145-156.

831 [138] C. Villanueva, B.G. Walker, M. Bertellotti, A matter of history: effects of tourism 832 on physiology, behaviour and breeding parameters in Magellanic Penguins 833 (Spheniscus magellanicus) at two colonies in Argentina, J. Ornithol. 153 (2012) 219834228.

835 [139] G.S. Fowler, Behavioral and hormonal responses of Magellanic penguins 836 (Spheniscus magellanicus) to tourism and nest site visitation, Biol. Conserv. 90 837 (1999) 143-149. 
838 [140] B.G. Walker, P.D. Boersma, J.C. Wingfield, Physiological and behavioral 839 differences in Magellanic Penguin chicks in undisturbed and tourist-visited locations 840 of a colony, Conserv. Biol. 5 (2005) 1571-1577.

841 [141] U. Ellenberg, A.N. Setiawan, A. Cree, D.M. Houston, P.J. Seddon, Elevated 842 hormonal stress response and reduced reproductive output in yellow-eyed penguins 843 exposed to unregulated tourism, Gen. Comp. Endocr. 152 (2007) 54-63.

844 [142] M.R. McClung, P.J. Seddon, M. Massaro, A.N. Setiawan, Nature-based tourism 845 impacts on yellow-eyed penguins Megadyptes antipodes: does unregulated visitor 846 access affect fledging weight and juvenile survival? Biol. Conserv. 119 (2004) 279$847 \quad 285$. 
849 Figure 1. Breeding cycle of the penguins. White, dark and dashed bars denote for 850 fasting on land, foraging at sea and feeding, chick rearing, respectively. Lettering 851 stands for species (see Table 1).

852 A/ Breeding cycle of the 18 penguin species and for both sexes ( $M$ stands for males 853 and $\mathrm{F}$ for females).

$854 \mathrm{~B} /$ Relative breeding cycle of the 18 penguin species. Mean courtship period is 855 defined as the shortest time between pair formation and the laying of the first egg. 856 Breeding cycle is defined as the time elapsed from the arrival of the penguins on their 857 breeding site to the fledging of the $\operatorname{chick}(\mathrm{s})$.

858 References for each species and periods:

\begin{tabular}{|l|l|l|l|}
\hline \multicolumn{1}{|c|}{ species } & \multicolumn{1}{|c|}{ pairing } & \multicolumn{1}{c|}{ incubation } & \multicolumn{1}{c|}{ chick rearing } \\
\hline$A f$ & {$[31]$} & {$[16,31,35]$} & {$[31,35]$} \\
\hline$A p$ & {$[17,18,59]$} & {$[17,18,35,59,63]$} & {$[17,18]$} \\
\hline Ec & {$[11,12,20,40]$} & {$[12,20]$} & {$[12,40)$} \\
\hline Ech & {$[32,44,60]$} & {$[32,44,60]$} & {$[32]$} \\
\hline$E m$ & {$[11,12,20,40]$} & {$[12,20]$} & {$[12,40]$} \\
\hline$E p$ & {$[12,22]$} & {$[12,22]$} & {$[12]$} \\
\hline$E r$ & {$[11,12,23]$} & {$[11,12,23]$} & {$[12]$} \\
\hline Es & {$[11,12,24,61]$} & {$[24,44,61]$} & {$[12]$} \\
\hline Esc & {$[23,42]$} & {$[11,12,48]$} & {$[12,25]$} \\
\hline Em & {$[62]$} & {$[11,62,64,65]$} & {$[71]$} \\
\hline Ma & {$[11]$} & {$[27,34]$} & {$[12]$} \\
\hline$P a$ & {$[12,29,52,53]$} & {$[11,12,35,50,52,66,67]$} & {$[12,35]$} \\
\hline$P a n$ & {$[12,29,50,53]$} & {$[12,50,53]$} & {$[12,53]$} \\
\hline$P p$ & {$[29]$} & {$[11,12,54,68,69]$} & {$[69]$} \\
\hline$S d$ & {$[56]$} & {$[14,56]$} & {$[56]$} \\
\hline$S h$ & {$[12]$} & {$[12]$} & {$[12]$} \\
\hline$S m$ & {$[30]$} & {$[30]$} & {$[12]$} \\
\hline$S m e$ & {$[12]$} & {$[70]$} & {$[12]$} \\
\hline
\end{tabular}

859

860 Figure 2. Repartition of the 18 species of breeding penguins (\%) according to the 861 Southern latitudinal gradient. 
863 Figure 3. Time elapsed from arrival at the breeding site (dashed line) and onset of 864 yolk formation for the 17 penguin species among the 18 ones. Lettering stands for 865 penguin species (see Table 1).

866

867 Table 1. Some biological characteristics of the 18 penguin species.

868 Body mass is the mean body mass of birds at the onset of the breeding season. 869 Mate fidelity is from one year to the consecutive year. For egg formation values, see 870 the Material and Methods section. The B-egg formation column represents the time 871 elapsed since the onset of the first yolk development. Abbreviations of the different 872 species are given in brackets after the scientific name of each species. Each 873 reference is indicated by a number in brackets. IUCN 2012 red list codes: 874 EN=endangered, LC=least concern, NT=near threatened, VU=vulnerable. 


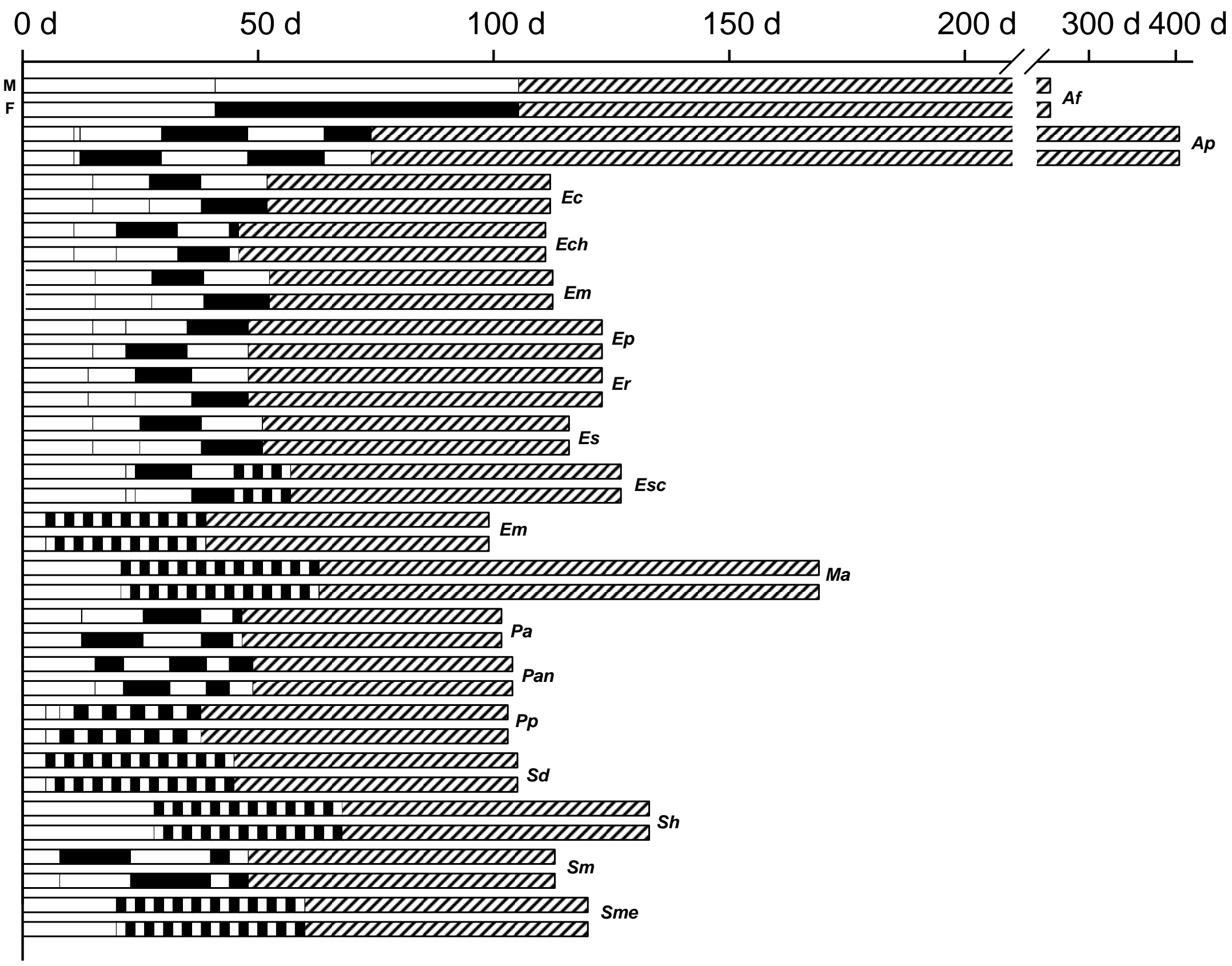




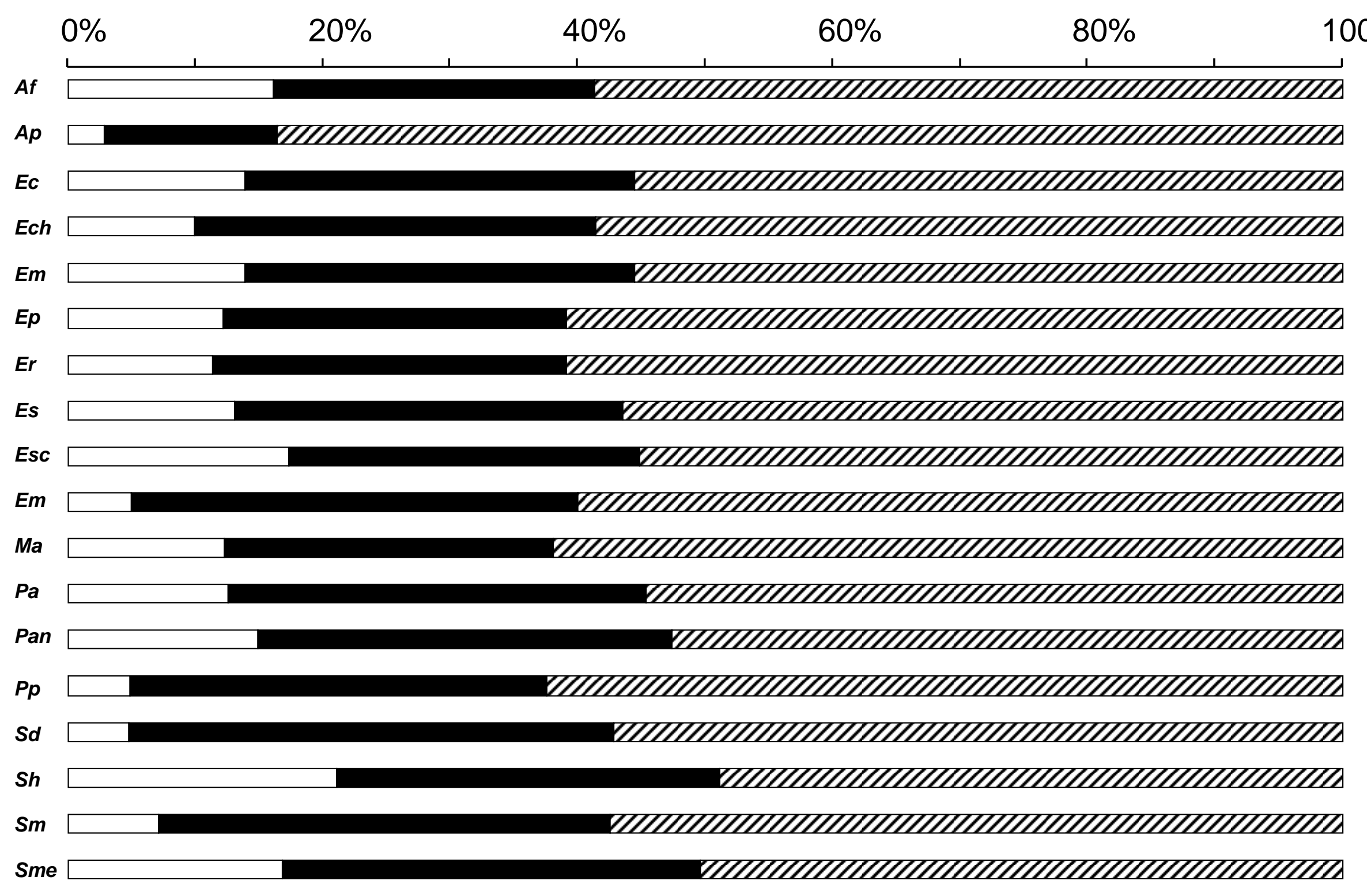




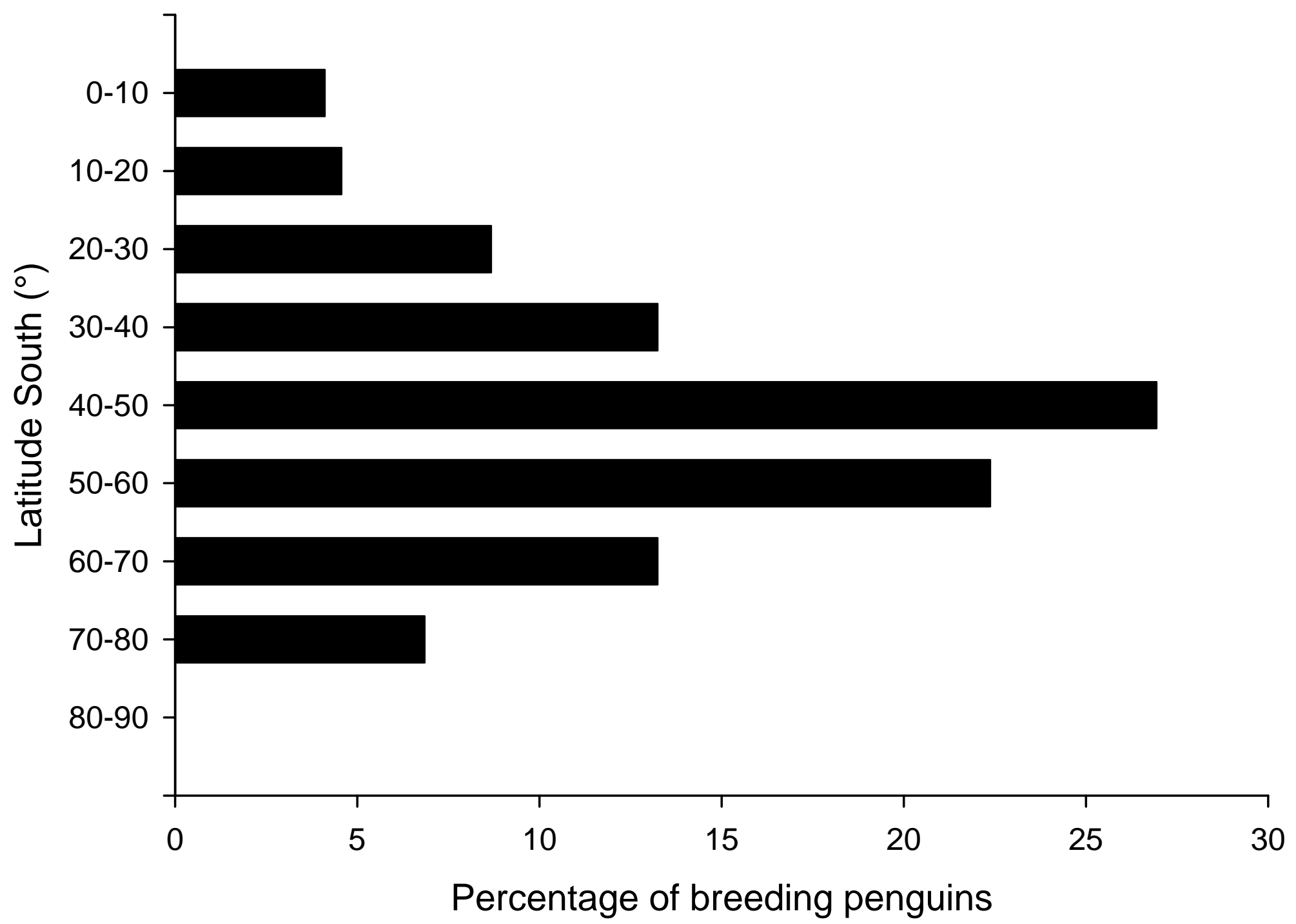




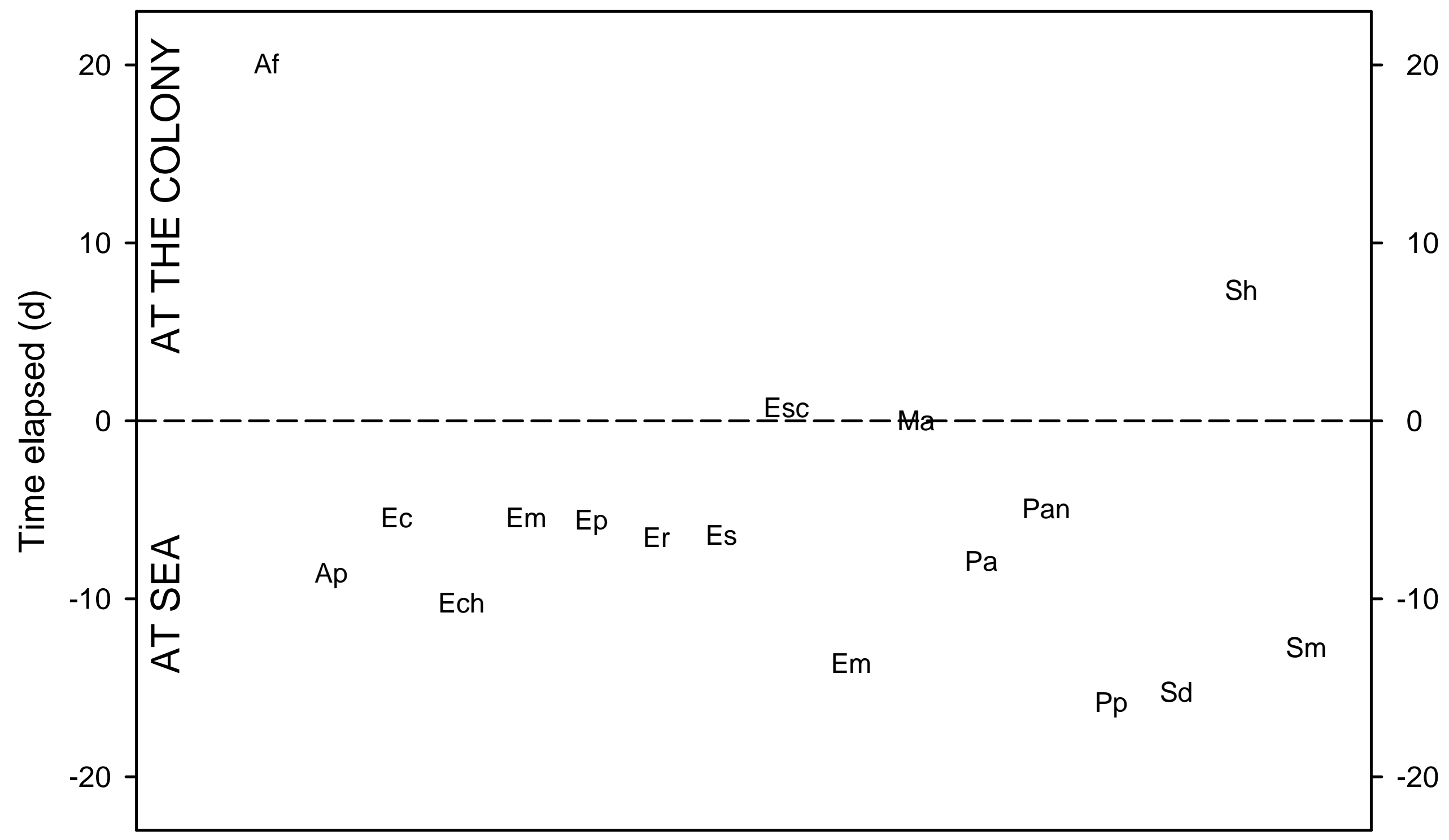

